\title{
The Healing Power of Laughter
}

\author{
Betty-Ann Heggie, B.Ed.
}

Toronto, Ontario, Canada.

"The most radical act anyone can commit is to be happy."

-Patch Adams

Patch Adams understood that laughter was important not only in healing, but also for filling the souls of those who care for patients. Each of us has a well within us, full of compassion, caring, and healing. Yet we daily face fear, pain, frustration, exhaustion, grief, and loss. All of these can deplete us while our patients are expecting more. There is perhaps no quicker way to replenish our wells than by the simple act of laughing.

As we take on the responsibilities of the world, many of us come to believe that laughter is something only children do. Research shows that children laugh about 400 times a day, but adults on average laugh only about 15 times. Especially in a healthcare environment plagued by burnout, we tend to become serious and don a stoic professional face. Some of us even believe that laughing makes us less professional.

As already mentioned, laughter brings physiological benefits to the body. It lessens people's pain, so if anything, we need to be spreading more healing laughter in all of our interactions. It is like a bee pollinating flowers and bringing them to life. But how can you as a busy hospitalist do this? Here are five ways to bring smiles and giggles to the health care:

- Smile. Smiling is contagious. So called "mirror neurons" (important in early human development) allow babies to mimic facial and emotional responses and fire in response to sensory input. Have you ever noticed when someone yawns, others in a room will yawn as well? Those are mirror neurons at work. Smiling and laughter activate mirror neurons in the

Corresponding Author: Ms. Heggie is the former Senior Vice President of PotashCorp(now Nutrien) and is a member of Canada's Top 100 Most Powerful Women Hall of Fame. E-mail; baheggie@bettyannheggie.com.

Received: March 11, 2019, Revised: March 15, 2019;

Accepted: March 15, 2019.

(c) 2019 Society of Hospital Medicine DOI 10.12788/jhm.3205 brain of primates and humans.1 This is why sitcoms often include laugh tracks-hearing the laughter makes us laugh. So laugh and watch: others will join you.

- Have some jokes ready. According to research those who can tell a good joke are viewed as more competent. Some data even suggests that employees with a good sense of humor are more likely to get a raise or promotion.2 However, humor can be tricky, as it is subjective. So, keep your jokes simple, nonoffensive, and short. Remember to know and read your audience.

- Plan silly times. Theme days replete with outfits or with sundries that may reflect your patients tastes or those of your inpatient teams can add smiles and joy while breaking a dismal routine.

- Be a good sport. Self-deprecation can be a way not only to bring a smile or two, but can help diffuse a tense situation. Being a good sport not only helps people spread joy to others but is a good way to be seen in a positive light by employers.

- Celebrate success and fun. Encourage smiling, pleasure, and laughing. When managers and administrators look like they are enjoying themselves, they set the company culture that it is a fun place to work.

Laughter is the best medicine. It not only heals others, but also helps lighten our daily loads, and brings a smile to our face and everyone we meet. Consider trying this opportunity to bring you and those around you a world of good.

Dissclosures: The author has nothing to disclose.

\section{References}

1. Rizzolatti G, Craighero, L. The mirror-neuron system. Annu Rev Neurosci. 2004;27(1):169-192. doi:10.1146/annurev.neuro.27.070203.144230.

2. Kristof-Brown AL. (2000). Perceived applicant fit: Distinguishing between recruiters' perceptions of person-job and person-organization fit. Personnel Psychol. 2000;53:643-671. 